3

4

5

\title{
Hematite Nanoparticles in Aquathermolysis: A Desulfurization Study of
}

\section{Thiophene}

(1)

Munawar Khalil ${ }^{\mathrm{a}, \mathrm{b}}$, Robert L. Lee $^{\mathrm{a}}, \mathrm{Ning}^{\mathrm{Liu}}{ }^{\mathrm{a} *}$

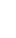
${ }^{a}$ Petroleum Recovery Research Center (PRRC), New Mexico Institute of Mining and Technology, 801 Leroy Place, 87801 Socorro, NM, USA
${ }^{\mathrm{b}}$ Department of Chemistry, New Mexico Institute of Mining and Technology, 801 Leroy Place, 87801 Socorro, NM, USA
*corresponding author: ningliu@ prrc.nmt.edu

\section{Abstract}

The potential usage of hematite nanoparticles as heterogeneous catalysts in aquathermolysis was investigated in this work. The desulfurization of thiophene was studied to investigate the catalytic activity of hematite in the aquathermolysis of heavy oil. It was found that reaction conditions, e.g., reaction time and temperature, ratio between thiophene and water, hematite nanoparticle size, catalyst concentration, and the presence of hydrogen donors, influenced the ability of hematite nanoparticles to decompose thiophene. Experimental results showed that thiophene conversion was increased with reaction time, temperature and catalyst concentration but decreased with thiophene/water ratio and particle size. Further analysis showed that the activity of the hematite nanocatalyst was also reduced in the presence of hydrogen donors. This is because hydrogen donors occupy the catalyst surface and block the catalytic sites. Furthermore, FTIR and XRD analyses revealed that thiophene underwent oxidative 
24 desulfurization to produce maleic acid, $\mathrm{SO}_{2}$ and $\mathrm{CO}_{2}$, whereas some areas of the hematite surface

25 were transformed into magnetite. However, this magnetite was re-oxidized back into hematite in

26 the presence of water as the source of active oxygen.

\section{Keywords}

29 Aquathermolysis, hematite, desulfurization, heterogeneous catalyst

\section{1. Introduction}

32 Heavy oil, a major component of total unconventional oil reserves, has become a major

33 research focus in the past decades because of the depletion of conventional light oil resources.

34 However, the exploration and production of heavy oils present special challenges compared to 35 conventional light oil, due to their physical and chemical properties. Heavy oil has very high 36 viscosity and is composed of a high amount of heteroatomic components such as resins and 37 asphaltene, which pose the main challenges to its production, transportation and processing. ${ }^{1}$ In 38 the past several years, many new technologies related to the optimization of heavy oil production

39 have been reported, such as thermal, chemical, and biochemical recovery. ${ }^{2-11}$ Comparison studies 40 of these methods suggest that thermal recovery via catalytic aquathermolysis is by far considered 41 as the most effective method to extract heavy oil. ${ }^{11}$ In general, catalytic aquathermolysis refers to 42 a process where steam and a catalyst (sometimes with hydrogen donors) are injected into the 43 reservoir rock in order to maximize heavy oil production by reducing its viscosity. The reduction 44 of the oil viscosity during this process is mainly due to the degradation of the large hydrocarbon 45 molecules such as asphaltene and resin in the heavy oil. ${ }^{11-14}$ Hydrodesulfurization (HDS), 
46 hydrodenitrogenation (HDN), hydrodemethylation, hydrocracking, and hydrogenation have been

47 reported during the aquathermolysis process. ${ }^{15-17}$

48 In catalytic aquathermolysis, different types of catalysts, such as iron-based catalysts, have

49 been widely reported. ${ }^{11}$ Various type of iron-based catalysts, such as $\mathrm{FeSO}_{4}, \mathrm{Fe}$-naphthenate,

$50 \mathrm{Fe}\left(\mathrm{CH}_{3} \mathrm{COCHCOCH}_{3}\right)_{3}$, iron (III) dodecylbenzene sulfonate, and iron-based ionic liquid, have

51 been successfully used in aquathermolysis. ${ }^{1,18-21}$ The mechanism of these iron-based catalysts to

52 catalyze aquathermolysis reaction has always been associated with $\mathrm{Fe}$ (II)/Fe (III)'s ability to

53 form a strong interaction with hydrocarbon molecules in heavy oil. For example, Rosales

54 reported that strong Fe-asphaltene interactions were formed in the presence of water and

55 electron-donor additives. ${ }^{22}$ Based on the calculation, these interactions occurred between Fe and

56 aromatics rings or $\mathrm{Fe}$ and heteroatoms ( $\mathrm{N}$ or $\mathrm{S}$ ) in asphaltene molecules. As a result, these

57 interactions would decrease bond energies (bond activations) of C-C, C-N, and C-S bonds in

58 asphaltene molecules, giving rise to the activation of these bonds for cracking, HDS and HDN

59 reactions. $^{22}$

60 It is widely known that hematite $\left(\alpha-\mathrm{Fe}_{2} \mathrm{O}_{3}\right)$ is one of the most naturally abundant type of iron

61 oxide mineral phases. ${ }^{23}$ Due to its unique physical and chemical properties, hematite has many

62 advantages such as nontoxicity, abundance, inexpensiveness and stability, and hence has been

63 studied in wide variety of applications. ${ }^{24-31}$ For oil and gas applications, recent studies have

64 shown that hematite can be used as a highly active heterogeneous catalyst in the catalytic steam

65 hydrocracking of petroleum residual oil. ${ }^{32-34}$ In this paper, the application of hematite

66 nanoparticles as catalyst in aquathermolysis was studied. Hematite nanoparticles were

67 synthesized using a simple and facile hydrothermal method according to our previous work. ${ }^{35}$

68 The effects of reaction time and temperature, amount of catalyst, ratio of thiophene/water, size of 
69 hematite nanoparticles, and the presence of a hydrogen donor were investigated in terms of

70 thiophene conversion. Moreover, the possible catalytic mechanism of thiophene on the hematite

71 nanoparticle surface was also investigated in this study.

72

\section{2. Experimental Methods}

\section{2.1. Materials}

75 For the synthesis of hematite nanoparticles, iron (III) chloride hexahydrate was purchased

76 from Alfa Aesar ${ }^{\circledR}$ and used as the iron source. Ammonium hydroxide and ethanol were

77 purchased from Sigma-Aldrich ${ }^{\circledR}$. For the aquathermolysis reaction, thiophene and hexane were

78 purchased from Sigma-Aldrich ${ }^{\circledR}$ and used as a representative oil feedstock and solvent,

79 respectively. While 1,2,3,4-tetrahydronaphthalene (tetralin) from Acros Organics ${ }^{\circledR}$ was used as

80 the hydrogen donor.

\subsection{Preparation of Hematite Nanocatalyst}

83 Hematite nanocatalysts were synthesized via hydrothermal method according to our previous

84 work. ${ }^{35}$ In this method, a mixture of aqueous iron (III) chloride and ammonium hydroxide

85 solution was prepared and heated at $120^{\circ} \mathrm{C}$ for 24 hours in a Teflon-lined stainless-steel

86 autoclave. The reaction products were then centrifuged and washed with distilled water and

87 ethanol three times, and finally dried under vacuum at $70^{\circ} \mathrm{C}$ for 12 hours. The hydrodynamic

88 particle size of the hematite nanoparticles was determined by Microtrac Zetatrac (Model

89 NPA152-31A), a dynamic light scattering (DLS) analyzer.

90

91 2.3. Characterization 
92 For the characterization of hematite nanocatalyst before and after aquathermolysis reaction,

93 FTIR and XRD analysis were performed. The FTIR spectra of samples were obtained using with

94 a Thermo Scientific Nicolet Avatar 370 DTGS FTIR Spectrometer. An X-ray diffraction study of

95 the nanoparticles was carried out using a PANalytical X'Pert Pro diffractometer equipped with

96 PIXcel detector (PANalytical B.V., Almelo, Netherlands). The measurements were performed on

97 zero-background silicon plates with the diffraction angle from $6^{\circ}$ to $70^{\circ}$ using $\mathrm{Cu} \mathrm{K} \alpha$ radiation.

98 Data were collected using X'Pert Data Collector software and processed using X'Pert HighScore

99 Plus (PANalytical B.V.). The BET surface areas of the synthesized hematite nanoparticles were 100 measured using a Micromeritics ASAP 2020 Surface Area and Porosity Analyzer. The BET101 specific surface area of the nanoparticles measured was $25.05 \mathrm{~m}^{2} / \mathrm{g}$.

102

103 2.4. Catalytic Desulfurization of Thiophene

104 To investigate the catalytic performance of hematite nanoparticles in aquathermolysis, 105 thiphene was desulfurized in a Teflon-lined autoclave-like reactor $(\sim 100 \mathrm{ml}$ in volume $)$ 106 fabricated in our laboratories. As the feedstock, thiophene in hexane solution with known initial 107 concentration was mixed with water (ratio 7:3) and used as the feedstock. Furthermore, $10 \%$ v. 108 of hydrogen donor (tetralin) was added into the mixture along with hematite nanoparticles as the 109 catalyst. The mixture was then heated up to different series of reaction temperature, i.e., $120^{\circ} \mathrm{C}-$ $110180^{\circ} \mathrm{C}$ and reaction times, i.e., $12-72$ hours. After the reaction, the reactor was cooled naturally

111 to room temperature. The catalytic performance of the hematite nanocatalyst was determined by 112 the conversion of thiophene after the reaction. An Agilent 7890A Gas Chromatograph equipped 113 with an Agilent J\&W HP-5 Column was used to measure thiophene concentration after the 114 reaction. In addition, a similar reaction procedure was carried out to study the effect of water in 
115 the reaction by changing the ratio of thiophene and water to 7:3, 1:1, and 3:7. Moreover, two

116 other reactions, i.e., with hydrogen gas (100 psi.) as the hydrogen donor and in the absence of

117 hydrogen donors, were conducted to study the effect of hydrogen donors in the desulfurization of

118 thiophene.

119 3. Results and Discussion

120 3.1. Catalytic Activity of Hematite Nanocatalyst

121 In order to study its potential application for catalysis of heavy oil in aquathermolysis, the

122 catalytic performance of hematite nanoparticles in thiophene desulfurization was investigated.

123 Figure 1a presents thiophene conversion at various temperatures during 12-72 hours of

124 desulfurization reaction. The results clearly indicated that thiophene started decomposing even at

125 a relatively low temperature $\left(120^{\circ} \mathrm{C}\right)$ on the hematite nanocatalyst surfaces. Results also showed

126 that thiophene decomposition increased with time up to 24 hours. After that, no significant

127 increment of conversion was observed when the reaction time was further increased to 48 and 72

128 hours. A review of the literature shows that different type of catalysts have been used in

129 desulfurization; for example, some transition metals or binary metals and their sulfides, either

130 supported or non-supported. ${ }^{36-40}$ However, these catalysts require high reaction temperature (>

$131300^{\circ} \mathrm{C}$ ) in order to ensure the effectiveness of thiophene decomposition. For example, a study by

132 Wang and Iglesia reported that a supported $\mathrm{Ru}$ cluster catalyst was successfully used for 133 desulfurization of thiophene in the presence of hydrogen gas. ${ }^{39}$ Based on their report, it was

134 found that $\mathrm{SiO}_{2}$ supported $\mathrm{Ru}$ metal cluster catalysts were able to effectively and selectively 135 catalyze both the desulfurization and hydrogenation of thiophene (reaction time: 15 hours; 136 catalyst concentration: $0.3 \%$ wt., temperature: $623 \mathrm{~K}$; and $3 \mathrm{MPa}$ of $\mathrm{H}_{2}$ ). In another study, it was

137 reported that an alumina supported bimetals catalyst of $\mathrm{Ni}-\mathrm{Mo}$ could convert about $55 \%$ of 
138 thiophene in a fixed bed reactor containing $200 \mathrm{mg}$ of catalyst at reaction temperature of $450^{\circ} \mathrm{C}$

139 with $20 \mathrm{ml} / \mathrm{min}$ flow rate of hydrogen for 8 hours. ${ }^{40}$ In this work using hematite nanoparticles as

140 a catalyst, our results show that $\sim 23 \%$ conversion of thiophene has already been achieved at

$141120^{\circ} \mathrm{C}$. Furthermore, an improvement on the catalytic performance was observed when the

142 reaction was carried out at higher temperatures (Fig. 1a). Based on the results, 34\% of thiophene

143 conversion was achieved when the reaction was carried out at $180^{\circ} \mathrm{C}$ for 72 hours.

144 The effect of hematite nanoparticle concentration on hematite's ability to convert thiophene

145 by desulfurization is presented in Fig. $1 \mathrm{~b}$. The results clearly display that the conversion of

146 thiophene was significantly affected by the amount of hematite nanocatalyst present in the

147 sample. Results also showed that no conversion of thiophene was observed in the absence of

148 hematite nanoparticles at the reaction temperature of $150^{\circ} \mathrm{C}$. This non-reactivity was due to the

149 stability of thiophene, as it is an aromatic compound and fairly stable towards hydro-

150 decomposition. A similar result was also observed in another group of sulfur-containing

151 compounds, a hydrodesulfurization study of 4,6-dimethylbenzothiophene over alumina-

152 supported Pt, Pd, and Pt-Pd catalyst. ${ }^{36}$ However, our results indicate that thiophene started

153 decomposing when even a very small amount of hematite nanoparticles $(0.0275 \%$ wt.) was

154 added. This result suggests that the reactivity of thiophene towards desulfurization was greatly

155 improved in the presence of hematite nanoparticles, which are essentially acting as a catalyst. It

156 is believed that the improvement of this reactivity is due to the activation of the C-S bond in

157 thiophene as thiophene interacts with the hematite surface. ${ }^{22,41}$ As expected, further

158 decomposition of thiophene was observed when the amount of catalyst was further increased to

$1590.05 \%$ wt. (Fig. 1b). This is true since more catalytically active surfaces could be provided as

160 more catalysts were added into the reaction. Thiophene conversion was further improved to 
$16122.4 \%$ when $0.075 \%$ wt. of hematite nanoparticles was used. Finally, when $0.1 \%$ wt. of hematite 162 nanoparticles were added, as high as $26.3 \%$ of thiophene conversion could be achieved. In 163 addition, the results also demonstrated that the effect of concentration on the catalytic activity of 164 hematite nanoparticles was slightly less significant at concentrations of catalyst beyond $0.05 \%$ 165 wt. This phenomenon could be the result of particle aggregation at high concentrations, which 166 ultimately reduces the availability of catalytically active surface for the catalysis. Therefore, 167 adding more catalysts than $0.05 \%$ wt. would only slightly increase the ability of hematite 168 nanoparticles to convert thiophene by desulfurization.

169 The effect of thiophene/water ratio and hematite nanoparticle size on the catalytic 170 performance of hematite nanoparticles in desulfurization reaction was also investigated. Figure 2 171 presents the desulfurization activity of hematite at different thiophene/water ratios and hematite 172 nanoparticle sizes. Figure 2a indicates that the amount of water present during the reaction had a 173 significant influence on the reactivity of thiophene towards desulfurization. The results clearly 174 show that the amount of thiophene conversion was gradually improved when more water was 175 introduced into the reaction system. In the reaction where thiophene was more dominant than 176 water, for example, thiophene/water ratio $=7: 3$, the conversion of thiophene was less effective.

177 Greater thiophene conversion was obtained when the thiophene/water ratio was 3:7. A similar 178 effect of water on the catalytic activity of hematite was also reported by Fumoto and co-workers 179 in their study on the catalytic steam cracking of heavy oil. ${ }^{32}$ It was believed that the crystalline 180 phase of the hematite surface was changed during the conversion of heavy oil to its light fraction. 181 Lattice oxygen in the hematite surface oxidized heavy oil to produce light oil and $\mathrm{CO}_{2}{ }^{32}$ As a 182 result of this oxidation, part of the hematite surface was reduced to magnetite. However, in the 183 presence of water steam, oxygen from water was supplied to the catalyst to reconstruct hematite 
184 back from magnetite. Therefore, hematite structure was maintained during the reaction when

185 enough oxygen species from water was provided. As a result, when more water was introduced

186 into the desulfurization, more oxygen could be generated from the water and better thiophene

187 desulfurization could be achieved. Figure $2 \mathrm{~b}$ presents the effect of hematite nanoparticle size on

188 the desulfurization of thiophene, showing that the activity of the catalyst was reduced by the

189 increments of catalyst particle size because the availability of surface area for catalytic reaction

190 is higher when catalyst size is reduced to nanoscale.

192 3.2. Role of Hydrogen Donor

193 In many aquathermolysis studies, several types of hydrogen donors such as tetralin,

194 cyclohexane, methylcyclohexane, and formic acid have been proven to improve heavy oil 195 degradation by donating active hydrogen to the reaction. ${ }^{11}$ The effect of the hydrogen donor on

196 hematite nanoparticle performance for thiophene conversion was investigated in this research.

197 Figure 3 shows the catalytic activity of hematite nanoparticles in the presence and absence of

198 tetralin and hydrogen gas as hydrogen donors. It was observed that the presence of a hydrogen

199 donor, both the tetralin and hydrogen gas, reduced the catalytic activity of hematite nanoparticles

200 to decompose thiophene. For example, when the reaction was carried out without a hydrogen

201 donor, $47 \%$ of thiophene was converted into other products. Conversely, when the reactions were

202 performed in the presence of tetralin or hydrogen gas, the conversions were at about $37 \%$ and

$20342.4 \%$, respectively (Fig. 3). It is believed that the overall desulfurization reaction involves

204 initial adsorption of thiophene onto the catalyst surface, which activates the molecule and is

205 followed by C-S bond scission to get the final products. ${ }^{42}$ The presence of a hydrogen donor can

206 transfer hydrogen to the reactant and improve the catalyst activity. However, our results 
207 indicated that the presence of a hydrogen donor decreased the catalytic activity. After carefully

208 examining the products with GC as tetralin was used as the hydrogen donor, it was observed that

209 the amount of tetralin remained the same before and after the reaction. Moreover, tetralin was

210 expected to convert into naphthalene with 1,2-dihydronaphthalene as intermediate if hydrogen

211 was transferred from tetralin to thiophene. ${ }^{43}$ However, analysis of the reaction products indicated

212 no sign of naphthalene or 1,2-dihydronaphthalene was obtained. This suggested that tetralin

213 remained unreactive during desulfurization when hematite nanoparticles were used as catalyst.

214 Therefore, it is possible that the C-S bond scission dominates the reaction of thiophene

215 decomposition on the hematite nanoparticle surface. When tetralin was introduced as the

216 hydrogen donor, the adsorption of tetralin onto the catalytic surface occupied the surface area

217 and hence decreased the possible adsorption of thiophene, resulting in the reduction of catalytic 218 activity.

219 Figure 3 also show a significant increment of thiophene conversion when hydrogen gas was

220 used as the hydrogen donor instead of tetralin (Fig. 3). This phenomenon can be explained by

221 taking into account the surface availability of hematite for the reaction due to adsorption of

222 tetralin and hydrogen. When hydrogen gas was used as the hydrogen donor, more hematite

223 surface was available for desulfurization because the size of the hydrogen molecule is

224 significantly smaller than the size of tetralin. In addition, it is also possible that the presence of 225 hydrogen gas can reduce some hematite to magnetite. Therefore, the reduction of catalytic 226 activity of hematite, comparing with no hydrogen donor, could be the result of both catalytic 227 surface occupation and catalyst reduction in the presence of hydrogen gas. 
In order to investigate the catalytic mechanism of thiophene decomposition with hematite

231 nanoparticles, the particles were collected before and after the reaction for further analysis using

232 FTIR. Figure 4 presents the FTIR spectra of hematite nanoparticles before and after reaction. The

233 IR spectra in Fig. 4a displayed only two sharp peaks at 525.24 and $435.96 \mathrm{~cm}^{-1}$, which

234 contributed to the $\mathrm{Fe}-\mathrm{O}$ stretch vibration and $\mathrm{Fe}-\mathrm{OH}$ bending vibration of $\alpha-\mathrm{Fe}_{2} \mathrm{O}_{3} \cdot{ }^{44,45}$ However,

235 several new peaks were observed after the reaction (Fig. 4b). The addition of these new peaks

236 may be due to the adsorption of reaction products produced from oxidative decomposition of

237 thiophene, i.e. maleic acid, $\mathrm{CO}_{2}$ and $\mathrm{SO}_{2}$. It has been reported that dicarboxylic acid, like maleic

238 acid, could be strongly adsorbed onto the surface of hematite, either by forming an interaction

239 with one of the carboxylate groups or with both of carboxylate groups. ${ }^{46}$ The presence of maleic

240 acid on the hematite surface is supported by the occurrence of a sharp and distinct peak at

$2411739.95 \mathrm{~cm}^{-1}$ due to the existence of the $\mathrm{C}=\mathrm{O}$ stretch (Fig. 4b). Meanwhile, a new peak at 1654

$242 \mathrm{~cm}^{-1}$ ascribed to the shifted asymmetric $v_{\text {as }}(\mathrm{COO}-)$ was observed. ${ }^{47}$ Furthermore, the broad peak

243 at $\sim 3000 \mathrm{~cm}^{-1}$ and sharp peak at $2972.32 \mathrm{~cm}^{-1}$ were clearly observed as a result of OH stretch and

$244 \mathrm{CH}$ stretch of maleic acid, respectively.

245 Further analysis of the IR spectra of the catalyst after the reaction suggested that $\mathrm{CO}_{2}$ was

246 produced as the other reaction product of desulfurization thiophene in addition to maleic acid.

247 The occurrence of $\mathrm{CO}_{2}$ as one of the products is proven by the appearance of weak and sharp

248 peaks at $2364.26 \mathrm{~cm}^{-1}$, which corresponds to the asymmetric stretch of $\mathrm{CO}_{2}{ }^{48}$ It is believed that

249 this occurrence of $\mathrm{CO}_{2}$ is due to the further decomposition of maleic acid at high temperature

250 during the reaction. In addition, the IR spectra also suggested that the other possible reaction

251 product was $\mathrm{SO}_{2}$, which is believed to be the result of the oxidative desulfurization of thiophene

252 in the surface of hematite. This is proven by the appearance of three strong IR absorptions at 
253 wave numbers between 1300 and $1400 \mathrm{~cm}^{-1}$, with features at $1375.96,1366.08$ and $1352.21 \mathrm{~cm}^{-1}$,

254 which can be ascribed as a result of adsorption of $\mathrm{SO}_{2}$ onto the surface of the hematite

255 nanoparticles. ${ }^{49,50}$ Moreover, this $\mathrm{SO}_{2}$ adsorption is also proven by the weak appearance of a 256 peak at 1511.3 and $1092.12 \mathrm{~cm}^{-1}$ as the result of the reaction of $\mathrm{SO}_{2}$ and surface hydroxyl on the 257 surface of the hematite. ${ }^{49}$ In addition, another peak around $1214.6 \mathrm{~cm}^{-1}$ ascribed to sulfate 258 adsorption onto the hematite surface was also observed due to the further oxidation of $\mathrm{SO}_{2}$ on the 259 oxygen rich hematite surface. ${ }^{51}$ Furthermore, results also show that the intensity of these 260 prominent peaks also decreased with reaction time and temperature due to desorption of $\mathrm{SO}_{2}$ and 261 sulfate from the surface (as shown in Figure 5).

262 XRD analysis was performed to investigate the crystalline phase of the catalyst before and 263 after the reaction. Figure 6 presents the XRD pattern of the catalyst collected before and after the 264 reaction. The diffraction patterns of the prior to the reaction can be unambiguously indexed as 265 the rhombohedral of hematite with no diffraction peaks for any other impurities (Fig. 6a). 266 However, Fig. 6b shows that a small amount of impurity peaks indexed as magnetite were 267 detected in the XRD pattern of the catalyst after the reaction was carried out at the 268 thiophene/water ratio of 7:3. However, these magnetite peaks disappeared when the reaction was 269 performed when the amount of water was more dominant than thiophene as the feedstock with 270 the ratio of 3:7 (as shown in Fig. 6c). These results suggest that there was a phase transformation 271 from hematite to magnetite as the result of desulfurization but it transformed back into hematite 272 when enough water was present. This phase transfer from hematite to magnetite, as discussed 273 above, resulted from the desulfurization reaction of thiophene with the lattice oxygen in hematite 274 crystals. $^{32}$ No diffraction peak for magnetite was observed when the desulfurization reaction was 
275 carried out at a thiophene/water ratio of 3:7 as more water was introduced into the reaction (Fig.

276 6c).

277 Therefore, based on the results from FTIR and XRD analysis, we know that thiophene 278 undergoes a catalytic oxidative desulfurization on the surface of oxygen-rich hematite 279 nanoparticles. The reaction of thiophene and oxygen on the surface of hematite nanoparticles is 280 believed to be responsible for the thiophene oxidative decomposition as it is adsorbed onto the 281 surface of nanoparticles. Thiophene oxidatively decomposes into maleic acid and $\mathrm{SO}_{2}$. As the 282 result of this thiophene oxidation, some part of the hematite surface is reduced into magnetite, 283 which is a form of iron oxide with a mixture of $\mathrm{Fe}^{2+}$ and $\mathrm{Fe}^{3+}$. But, in the presence of more water 284 in the form of steam as the source of the oxygen, a part of the hematite surfaces that were 285 reduced into magnetite are oxidized back to hematite. The possibility of active oxygen transfer 286 from water to catalyst surface and then finally to the feedstock (in this case thiophene) is also 287 supported by theoretical studies since considerably little energy is required for the water splitting 288 on the surface of magnetite. ${ }^{52,53}$ Hence, the overall catalytic cycle mechanism for the oxidative 289 DS of thiophene using hematite nanoparticles can be expressed as shown in Fig. 7.

\section{Conclusion}

292 The catalytic activity of hematite nanoparticles has been successfully investigated and found 293 to be catalytically active in desulfurization of thiophene. Results demonstrate that hematite 294 nanoparticles are good catalysts for decomposing thiophene even at a low temperature of $120^{\circ} \mathrm{C}$.

295 Based on analyses, it was found that the catalytic performance of hematite nanoparticles in the 296 desulfurization of thiophene increases with time and temperature of the reaction and the 297 concentration of catalyst. Meanwhile, it decreases with ratio of thiophene/water and size of the 
298 particles. Results also show that the presence of hydrogen donor (tetralin and hydrogen gas)

299 reduced the catalytic activity of hematite due to their occupation of the hematite catalytic site

300 without any participation in the desulfurization. Furthermore, FTIR spectra indicated that

301 thiophene undergoes oxidative desulfurization to produce maleic acid, $\mathrm{SO}_{2}$ and $\mathrm{CO}_{2}$. In addition,

302 XRD analysis revealed that the catalytic process involved a cyclic phase transformation of some

303 of the hematite to magnetite as thiophene was oxidatively decomposed into its products, and re-

304 oxidation of magnetite to hematite in the presence of water as the source of active oxygen.

305

306 Acknowledgement

307 We gratefully acknowledge the support of the Department of Energy through the National 308 Energy Technology Laboratory under contract number DE-FE0005979. The authors appreciate 309 the aid of Liz Bustamante for her assistance in editing this manuscript.

\section{Reference}

312 1. Desouky, S.; Al Sabagh, A.; Betiha, M.; Badawi, A.; Ghanem, A.; Khalil, S. Catalytic 313 aquathermolysis of Egyptian heavy crude oil. Inter. J. Chem. Mater. Sci. Eng. 2013, 7, 1-6.

314 2. Premuzic, E.T.; Lin, M.S. Induced biochemical conversions of heavy crude oils. J. Petrol. 315 Sci. Eng. 1999, 22, 171-180.

316 3. Patras, L.E.; Webster, I.A. The microbial upgrading of model heavy oils. Stud. Surf. Sci. $317 \quad$ Catal. 1989, 50, 273-288.

318 4. Bhadra, A.; Scharer, J.M.; Moo-Young, M. Microbial desulfurization of heavy oils and 319 bitumen. Biotechnol. Adv. 1987, 5, 1-27. 
320 5. Xia, T.X.; Greaves, M. Upgrading Athabasca tar sand using toe-to-heel air injection. $J$. $321 \quad$ Can. Petrol. Technol. 2002, 41, 51-57.

322 6. Pineda-Perez, L.A.; Carbognani, L.; Spencer, R.J.; Maini, B.; Pereira-Almao, P. 323 Hydrocarbon depletion of Athabasca core at near steam-assisted gravity drainage (SAGD) 324 conditions. Energ. Fuels. 2010, 24, 5947-5954.

325 7. Lee, D.G.; Noureldin, A. Effect of water on the low-temperature oxidation of heavy oil. $326 \quad$ Energ. Fuels. 1989, 3, 713-715

327 8. Bagci, S.; Kok, M.V. In-situ combustion laboratory studies of Turkish heavy oil reservoirs. $328 \quad$ Fuel. Process. Technol. 2001, 74, 65-79.

329 9. Shokrlu, Y.H.; Maham, Y.; Tan, X.; Babadagli, T.; Gray, M. Enhancement of the 330 efficiency of in situ combation technique for heavy-oil recovery by application of nickel $331 \quad$ ions. Fuel. 2013, 105, 397-407.

332 10. Chen, Y.; Wang, Y.; Lu, J.; Wu, C. The viscosity reduction of nano-keggin- $\mathrm{K}_{3} \mathrm{PMo}_{12} \mathrm{O}_{40}$ in 333 catalytic aquathermolysis of heavy oils. Fuel $\mathbf{2 0 0 9} 88,1426-1434$.

334 11. Maity, S.K.; Ancheyta, J.; Marroquin, G. Catalytic aquathermolysis used for viscosity 335 reduction of heavy crude oil: a review. Energ. Fuels. 2010, 24, 2809-2816.

336 12. Chen, Y.; Wang, Y.; Wu, C.; Xia, F. Laboratory experiments and field tests of amphiphilic 337 metallic chelate for catalytic aquathermolysis of heavy oil. Energ. Fuels. 2008, 22, 1502$338 \quad 1508$.

339 13. Clark, P.D.; Hyne, J.B. Steam-oil chemical reactions: mechanism for the aquathermolysis $340 \quad$ of heavy oil. AOSTRA J. Res. 1984, 1, 15-20.

341 14. Clark, P.D.; Hyne, J.B. Studies on the chemical reactions of heavy oils under steam 342 stimulation condition. AOSTRA J. Res. 1990, 29, 23-39. 
343 15. Liu, C.T. Aquathermolysis of heavy oil model compounds. Adv. Mat. Res. 2011, 263, 732344735.

345 16. Katritzky, A.R.; Murugam, R.; Balasubramanian, M.; Greenhill, J.V.; Siskin, M.; Brons, G. 346 Aqueous high-temperature chemistry of carbo- and heterocycles. 16. ${ }^{1}$ model sulfur 347 compounds: a study of hydrogen sulfide generation. Energ. Fuels 1991, 5, 823-834.

348 17. Katritzky, A.R.; Murugam, R.; Balasubramanian, M.; Greenhill, J.V.; Siskin, M.; 349 Olmsteed, W.N. Aqueous high-temperature chemistry of carbo- and heterocycles. $21 .^{1}$ 350 reactions of sulfur-containing compounds in supercritical water at $460^{\circ} \mathrm{C}$. Energ. Fuels. $351 \quad \mathbf{1 9 9 4 , 8 , 4 9 8 - 5 0 6 .}$

352 18. Clark, P.D.; Dowling, N.I.; Lesage, K.L.; Hyde J.B. Chemistry of organosulphur 353 compound types occurring in heavy oil sands, 5. Reaction of thiophene and 354 tetrahydrothiophene with aqueous group VIIIB metal species at high temperature. Fuel. $355 \quad \mathbf{1 9 8 7}, 66,1699-1702$.

356 19. Mohammad, A.A.; Mamora, D.D. Paper SPE/PS/CHOA 117604 in SPE/PS/CHOA 357 International Thermal Operation and Heavy Oil Symposium, Calgary, Alberta, 20-23 $358 \quad$ October 2008

359 20. Yufeng, Y.; Shuyuan, L.; Fuchen, D.; Hang, Y. Change of asphaltene and resin properties $360 \quad$ after catalytic aquathermolysis. Pet. Sci. 2009, 6, 194-200.

361 21. Nares, H.R.; Schacht-Hernandez, P.; Ramirez-Garnica, M.A.; Cabrera-Reyes, M.C. SPE 362108676 in International Oil Conference and Exhibition, Veracruz, Mexico, 27-30 June 363 2007. 
22. Rosales, S.; Machín, I.; Sánchez, M.; Rivas, G.; Ruette, F. Theoretical modeling of molecular interactions of iron with asphaltenes from heavy crude oil. J. Mol. Catal. A: Chem. 2006, 246, 146-153.

367 23. Cornell, R.M.; Schwertmann, U. The Iron Oxides: Structure, Properties, Reactions, Occurances and Uses ( $2^{\text {nd }}$ edition). Wiley-VCH Verlag GmbH \& Co. KGaA, Weinheim : 2003.

24. Young, K.M.H.; Klahr, B.M.; Zandi, O.; Hamann, T.W. Photocatalytic water oxidation with hematite electrodes. Catal. Sci. Tech. 2013, 3, 1660-1671.

372 25. Lodhia, J.; Mandarano, G.; Ferris, N.J.; Eu, P.; Cowell, S.F. Development and use of iron oxide nanoparticles (part 1): synthesis of iron oxide nanoparticles for MRI. Biomed. Imaging. Interv. J. 2010, 6, e12.

26. Chen, L.; Xie, J.; Aatre, K.R.; Yancey, J.; Srivatsan, M.; Varadan, V.K. SPIE 8548 in Nanosystems in Engineering and Medicine, Incheon, Republic of Korea, 10 September 2012.

27. Brezesinski, K.; Haetge, J.; Wang, J.; Mascotto, S.; Reitz, C.; Rein, A.; Tolbert, S.H.; Perlich, J.; Dunn, B.; Brezesinski, T. Ordered mesoporous $\alpha-\mathrm{Fe}_{2} \mathrm{O}_{3}$ (hematite) thin-film electrodes for application in high rate rechargeable lithium batteries. Small. 2011, 7, 407414.

28. Gialanella, G.; Belli, R.; Dalmeri, G.; Lonardelli, I.; Mattarelli, M.; Montagna, M.; Toniutti, L. Artificial or natural origin of hematite-based red pigments in archaelogical contexts: the case of Riparo Dalmeri (Trento, Italy). Archaeometry. 2011, 53, 950-962. 
29. Cuong, N.D.; Hoa, T.T.; Khieu, D.Q.; Hoa, N.D.; Hieu, N.V. Gas sensor based on nanoporous hematite nanoparticles: effect of synthesis pathways on morphology and gas sensing properties. Curr. App. Phys. 2012, 12, 1355-1360.

30. Simeonidis, K.; Gkinis, Th.; Tresintsi, S.; Martinez-Boubeta, C.; Vourlias, G.; Tsiaoussis, I.; Stavropoulos, G.; Mitrakas, M.; Angelakeris, M. Magnetic separation of hematite-coated $\mathrm{Fe}_{3} \mathrm{O}_{4}$ particles used as arsenic adsorbents. Chem. Eng. J. 2011, 168, 1008-1015.

31. Hong, Y.R.; Liu, Z.; Al-Bukhari, S.F.B.S.A.; Lee, C.J.J.; Yung, D.L.; Chi, D.; Hor, T.S.A. Effect of oxygen evolution catalysts on hematite nanorods for solar water oxidation. Chem. Commun. 2011, 47, 10653-10655.

32. Fumoto, E.; Sato, S.; Takanohashi, T. In Nanocatalyst for Fuels and Chemicals; Dalai, A.K.; ACS Symposium Series; American Chemical Society: Washington, DC, 2012, pp 75-85.

33. Fumoto, E.; Tago, T.; Tsuji, T.; Masuda, T. Recovery of useful hydrocarbons from petroleum residual oil by catalytic cracking with steam over zirconia-supporting iron oxide catalyst. Energ. Fuels. 2004, 18, 1770-1774.

34. Fumoto, E.; Tago, T.; Masuda, T. Production of lighter fuels by cracking petroleum residual oils with steam over zirconia-supporting iron oxide catalysts. Energ. Fuels. 2006, $20,1-6$.

35. Khalil, M.; Yu, J.; Liu, N.; Lee, R.L. Hydrothermal synthesis, characterization, and growth mechanism of hematite nanoparticles. J. Nanopart. Res. 2014, 16, 2362.

36. Niquille-Röthlisberger, A.; Prins, R. Hydrodesulfurization of 4,6-dimethylbenzothiophene and dibenzothiophene over alumina-supported Pt, Pd, and Pt-Pd catalysts. J. Catal. 2006, 242, 207-216. 
37. Ishihara, A.; Dumeignil, F.; Lee, J.; Mitsuhashi, K.; Qian, E.K.; Kabe, T. Hydrodesulfurization of sulfur-containing polyaromatic compound in light gas oil using noble metal catalysts. App. Catal. A. 2005, 289, 163-173.

38. Wang, H.; Iglesia, E. Mechanism and site requirements of thiophene hydrodesulfurization catalyzed by supported Pt clusters. Chem. Cat. Chem. 2011, 3, 1166-1175.

39. Wang, H.; Iglesia, E. Thiophene hydrodesulfurization catalyst on supported Ru clusters: mechanism and site requirements for hydrogenation and desulfurization pathways. J. Catal. 2010, 273, 245-256.

40. Al-Megran, H.A. Hydodesulfurization of thiophene over bimetallic Ni-Mo sulfide catalyst prepared by different methods. Arab. J. Sci. Eng. 2009. 34, 55-66.

41. Dzade, N.Y.; Roldan, A.; de Leeuw, N.H. A density functional theory study of the adsorption of benzene on hematite $\left(\alpha-\mathrm{Fe}_{2} \mathrm{O}_{3}\right)$ surfaces. Minerals. 2014, 4, 89-115.

42. Angelici, R.J. Heterogeneous catalysis of the hydrodesulfurization of thiophene in petroleum: an organometallic perspective of the mechanism. Acc. Chem. Res. 1988, 21, 387-394.

43. Ovalles, C.; Vallejos, C.; Vasquez, T.; Rojas, I.; Ehrman, U.; Benitez, J.L.; Martinez, R. Downhole upgrading of extra-heavy crude oil using hydrogen donors and methane under steam injection conditions. Pet. Sci. Technol. 2003, 21, 255-274.

44. Lu, B.; Li, P.; Liu, H.; Zhao, L.; Wei, Y. Synthesis of hexagonal pyramidal columnar hematite particles by a two-step solution route and their characterization. Powder Technol. 2012, 215-216, 132-136.

45. Khalil, M.; Yu, J.; Liu, N.; Lee. R.L. Non-aqueous modification of synthesized hematite nanoparticles with oleic acid. Colloid Surface A. 2014, 453, 7-12. 
431 46. Duckworth, O.W.; Martin, S.T. Surface complexation and dissolution of hematite by $\mathrm{C}_{1}-\mathrm{C}_{2}$

432 dicarboxylic acid at $\mathrm{pH}=5.0$. Geochim. Cosmochim. Ac. 2001, 65, 4289-4301.

433 47. Hwang, Y.S.; Lenhart, J.J. Adsorption of C4-dicarboxylic acids at the hematite/water $434 \quad$ interface. Langmuir. 2008, 24, 13934-13943.

435 48. Murphy, R.; Lammers, K.; Smirnov, A.; Schoonen, M.A.A.; Strongin, D.R. Hematite 436 reactivity with supercritical $\mathrm{CO}_{2}$ and aqueous sulfide. Chem. Geol. 2011, 283, 210-217.

437 49. Zhang, X.; Zhuang, G.; Chen, J.; Wang, Y.; Wang, X.; An, Z.; Zhang, P. Heterogeneous 438 reaction of sulfur dioxide on typical mineral particles. J. Phys. Chem. B. 2006, 110, 12588$439 \quad 12596$.

440 50. Fu, H.; Wang, X.; Wu, H.; Yin, Y.; Chen, J. Heterogeneous uptake and oxidation of $\mathrm{SO}_{2}$ on 441 iron oxides. J. Phys. Chem. C. 2007, 111, 6077-6085.

442 51. Hug, S.J. In situ Fourier transform infra red measurements of sulfate adsorption on 443 hematite in aqueous solutions. J. Colloid Inter. Sci. 1997, 188, 415-422.

444 52. Parkinson, G.S.; Novotnỳ, Z.; Jacobson, P.; Schmid, M.; Diebold, U. Room temperature 445 water splitting at the surface of magnetite. J. Am. Chem. Soc. 2011, 133, 12650-12655.

446 53. Liu, S.; Wang, S.; Li, W.; Guo, J.; Guo, Q. Water dissociation on magnetite (001) films. J. 447 Phys. Chem. C. 2013, 117, 14070-14074. 